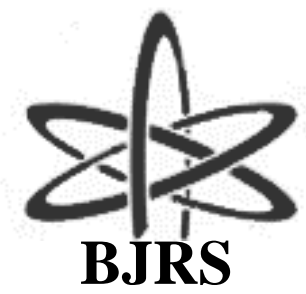

\author{
BRAZILIAN JOURNAL \\ $\mathrm{OF}$ \\ RADIATION SCIENCES \\ 07-01A (2019) 01-10
}

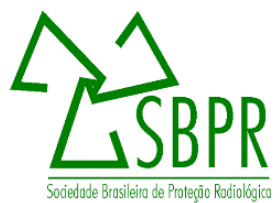

\title{
Study for pediatric protocol optimization in chest CT scan
}

\author{
Frederico, M. ${ }^{\mathrm{a}, \mathrm{b}}$, Banguero Y. ${ }^{\mathrm{a}, \mathrm{c}}$, Cerecetto, H. ${ }^{\mathrm{a}}$, Santana, P. C $\mathrm{C}^{\mathrm{b}}$. Oliveira, \\ F.A. ${ }^{d}$, Mourao, A. P. ${ }^{\text {b,d }}$ \\ ${ }^{a}$ Centro de Investigaciones Nucleares, Universidad de la República, Montevideo, Uruguay. \\ ${ }^{b}$ Departamento de Engenharia Nuclear - UFMG, Belo Horizonte, Brasil \\ ${ }^{c}$ Servicio de Radioterapia Oncológica, Hospital de Clínicas, Universidad de la República, Montevideo, Uruguay \\ ${ }^{d}$ Centro de Engenharia Biomédica-CEFET-MG, Belo Horizonte, Brasil \\ mfrederico@cin.edu.uy
}

\begin{abstract}
Radiological exams are increasingly used in clinic for diagnostic analysis of different types of pathologies. These exams are associated with a dose that is received by the patient. In addition, the risks in exposure to ionizing radiation are different according to the group which the individual belongs. According to age, the group of children is more radiosensitive than adults. In this work we have obtained values of the air-weighted kerma index for chest scans studies in a General Electric Computed Tomography (CT) scanner model Discovery with 64-channels. Using an adult protocol, two scans have been performed, one using a cylinder standard PMMA phantom while the second one has used an oblong chest phantom designed for a two year old pediatric patient. Furthermore, other protocols have been selected with a constant voltage but changing the $\mathrm{X}$-ray tube current and maintaining the image quality in order to obtain a reduction in the received dose by the pediatric patient. The use of the adult protocol in the child phantom has an air-weighted kerma index of $89.5 \%$ greater than the kerma index using the adult phantom. Due small patients receive higher doses; the use of specific protocols for children is important for the dose reduction in CT tests. An optimized pediatric chest protocol is presented, obtaining as a result dose reduction compared with the adult protocol of $62.2 \%$. Because of different CT scanners characteristics and in order to optimize protocols regard to dose and diagnostic image quality, it is necessary to use pediatric phantoms in health centers.
\end{abstract}

Keywords: dosimetry, phantoms, radioprotection, computed tomography. 


\section{INTRODUCTION}

Computed Tomography (CT) is used for observing human tissue anatomy. A CT scanner produces body section images that allow observing the patient's anatomy and lesions inside the body. This equipment is utilized in adult patients and in children. The beginning of this technology started in 1970, with an evolutionary process in time, having the beginning of the helical era in the first years of the nineties decade. The capacity of these scanners has been developed thus generating new and diverse applications medical conditions. With these technological advances, the number of CT users worldwide has also increased.

Approximately, 80 millions of tomography tests are made annually in the United States, where 7 million occurs for children according to the AAPM ${ }^{1}$. A study by the IAEA (International Atomic Energy Agency) carried out in 29 countries, including Latin American countries, shows that there is a tendency to increase these studies, where $75 \%$ of them are head scans. In addition, there is a lack in the existence and use of guidelines for decision making regarding the use of tomography in pediatric patients ${ }^{2}$. Depending on the scanner type and who handles them, it is common to observe the use of adult protocols in pediatric patients, especially in countries where there are no firm regulations.

Because of the awareness generated by these issues, there are a number of organizations working on it, for example "Alliance for Radiation Safety in Pediatric" representing 750,000 people working on medical imaging. Together with the IAEA and other organizations, they aim to promote radiological protection and raise awareness of the application of CT studies in pediatric patients, in addition to promoting the justification of these studies and their optimization (balancing the dose received by the patient regarding image quality) ${ }^{1}$.

This work aims to contribute knowledge in this direction. We have compared the values obtained from the Weighted Computed Tomography Dose Index for a standard adult protocol first applied to an adult PMMA phantom followed by the application of the same protocol, but on a pediatric phantom constructed to recreate a two years old chest.

In order to reduce the dose receiving for the pediatric patient, the electric current $(\mathrm{mA})$ has been varied for a constant voltage $(\mathrm{kV})$ maintaining an image quality for proper diagnosis in order to obtain an optimized protocol. 


\section{MATERIALS AND METHODS}

For the development of this work, experimental measures have been obtained using two chest phantoms, both made in PMMA (poly methyl methacrylate). The cylindrical phantom is the standard used to obtain the Computed Tomography Dose Index (CTDI). A second phantom developed by the Centro de Engenheria Biomédica (CENEB) was made based on the size of the chest, in the axillary region, for a two years old patient. Fig. 1 shows the image of these phantoms placed in the CT scanner isocenter.

Figure 1: PMMA chest phantom images, (a) adult standard (b) oblong for two years old pediatric patient, placed in the gantry.

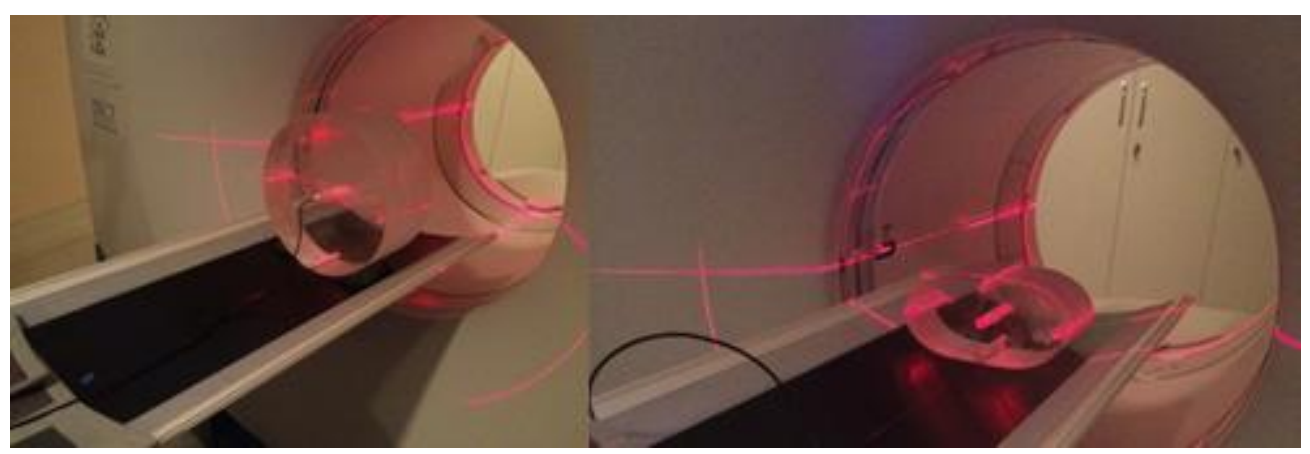

(a)

(b)

Both phantoms have five cylindrical spaces with a diameter of $12.7 \mathrm{~mm}$ for the placement of the pencil ionization chamber, one of them is central and the remaining four are peripheral lagged of $90^{\circ}$. Using the similarity in the positions of an analog clock, peripheral spaces were named 3, 6, 9, and 12 , according to the chamber position during the irradiation of the central slice. The centers of these cylindrical spaces are located $10 \mathrm{~mm}$ from the edge of each phantom. The adult phantom has a cylindrical shape with a diameter of $320 \mathrm{~mm}$ and a length of $150 \mathrm{~mm}$, while the second has an oblong shape, with dimensions $80 \mathrm{~mm}$ wide by $55 \mathrm{~mm}$ high and $150 \mathrm{~mm}$ in length. An image with a central slice of the two phantoms is shown in Figure 2. 
Figure 2: Central slice axial images of the phantoms

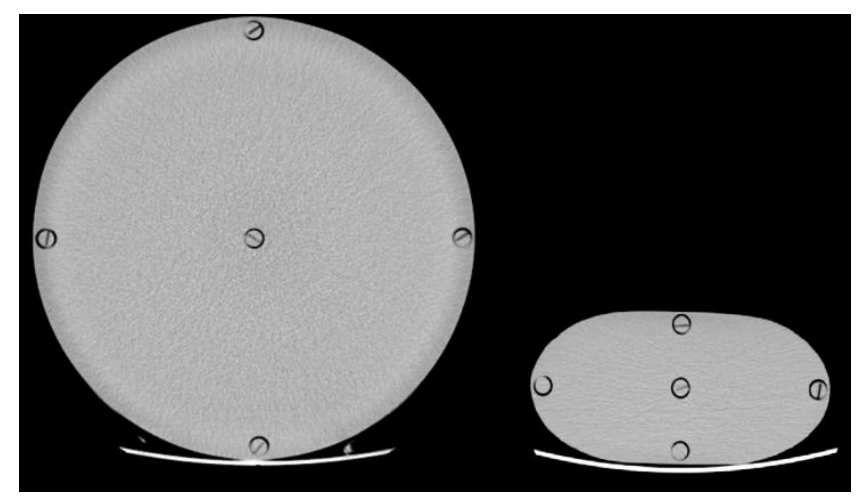

All measurements were conducted in a 64-channel GE Scanner Model Discovery. The phantoms have been positioned in the thomograph isocenter through the room lasers besides the tomograph lasers. After this a scout was made in order to check the correct alignment of the phantoms as well as demarcate the central slice position. The protocol parameters used for irradiation of the central slice in axial mode for both phantoms are shown in table 1:

Table 1: Chest protocol selected parameters

\begin{tabular}{cccccc}
\hline $\begin{array}{c}\text { Acquisition } \\
\text { Mode }\end{array}$ & $\begin{array}{l}\text { Voltage } \\
(\mathbf{K v})\end{array}$ & $\begin{array}{l}\text { Charge } \\
(\mathbf{m A s})\end{array}$ & $\begin{array}{l}\text { Current } \\
(\mathbf{m A})\end{array}$ & $\begin{array}{c}\text { Slice thick- } \\
\text { ness } \\
(\mathbf{m m})\end{array}$ & $\begin{array}{r}\text { Rotation } \\
\text { time }\end{array}$ \\
\hline Axial & 120 & 100 & 200 & 10 & 0.5 \\
\hline
\end{tabular}

For protocols optimization with respect to the dose, the same conditions of positioning previously mentioned were followed. In this work, a noise below $1 \%$ was considered acceptable for images with $5 \mathrm{~mm}$ tomography reconstruction. From the chest protocol used by the hospital tomography service presented in Table 2, successive examinations have been made with the pediatric phantom, reducing the tube current as much as possible, since this is the first direct way of decreasing the dose given to the patient ${ }^{4}$, and verifying the noise in the central image of the phantom, until finding the optimized protocol presented in Table 2. 
Table 2: Chest protocol selected parameters

\begin{tabular}{ccccccc}
\hline Protocol & $\begin{array}{c}\text { Voltage } \\
(\mathbf{K v})\end{array}$ & $\begin{array}{c}\text { Charge } \\
(\mathbf{m A s})\end{array}$ & $\begin{array}{c}\text { Current } \\
(\mathbf{m A})\end{array}$ & $\begin{array}{c}\text { Slice } \\
\text { thickness } \\
(\mathbf{m m})\end{array}$ & $\begin{array}{c}\text { Rotation } \\
\text { time } \\
(\mathbf{s})\end{array}$ & Pitch \\
\hline Adult & 120 & 100 & 350 & 20 & 0.8 & 1.375 \\
\hline Optimizaded & 120 & 56 & 70 & 20 & 0.8 & 1.375 \\
\hline
\end{tabular}

\subsection{Calculation of dose indexes}

For the measurement of the doses given in the protocols, a pencil ionization chamber RADCAL- model 10x6-3CT $\mathrm{N}^{\circ}$ 05-0014 of $100 \mathrm{~mm}$ long was used with a dose measuring module Accu-dose digitizer ADDM $+\mathrm{N}^{\circ} 47-0758$, of the same company. This chamber was placed in the central opening as well as in the peripherals, in each one of the phantoms in order to obtain the air kerma readings. At each acquisition step, the remaining openings were filled using PMMA rods. Four measurements of air kerma (mGy) were taken per position inside the phantom.

The readings allowed to compute the Computed Tomography Dose Index CTDI 100 in air, usually used for conducting dosimetric studies. These indices allow to quantify the total radiation in a length of $100 \mathrm{~mm}$, which corresponds to the length of the ionization chamber type pencil, which is defined by equation $(1)^{5,6}$ :

$$
C T D I=\frac{1}{T} \int_{-\infty}^{+\infty} D(z)
$$

Where $\mathrm{T}$ is the slice thickness and $\mathrm{D}(\mathrm{z})$ corresponds to the dose measured along the $\mathrm{z}$-axis (the rotation of the X-ray tube). For experimental purposes equation (2) was used:

$$
C T D I=\frac{M .100 \mathrm{~mm}}{N T}
$$

Where:

M: is the reading obtained for a single rotation scan, corrected by pressure and temperature 
$100 \mathrm{~mm}$ : is the active length of the ionization chamber.

$\mathrm{N}$ : is the number of cuts for a single rotation used for multi-slice tomograph.

T: Cutting thickness in $\mathrm{mm}$.

After obtaining the different CTDI on the five positions inside the phantoms, the Weighted Computed Tomography Dose Index was calculated by equation $(3)^{5,6}$ :

$$
C T D I_{W}=\frac{1}{3} \cdot(C T D I c+2 \cdot C T D I p)
$$

Where $\mathrm{CTDI}_{\mathrm{C}}$ and $\mathrm{CTDI}_{\mathrm{P}}$ correspond to the dose indexes measured in the center and the periphery of each phantom. This index indicates the dose attributable to a slice in the $\mathrm{x}-\mathrm{y}$ plane. To quantify the average dose of radiation in the $x-y-z$ volume, attributable to a unitary displacement of the table in the z-axis, the Volumetric Computed Tomography Dose Index is defined by the equation (4). This magnitude is widely used as a dose indicator for a specific protocol, because it takes into account the pitch information ${ }^{7}$.

$$
C T D I_{V O L}=\frac{1}{p i t c h} \cdot C T D I_{W}
$$

\subsection{Calculation of image noise}

For noise $(N)$ analysis in the PMMA phantom, the following relationship is used by taking four representative ROIs in the central slice image of the pediatric phantom using the equation $(5)^{7,8}$.

$$
N \%=\frac{\sigma}{\text { meanROIval }+1000} \cdot 100
$$

Where:

$N \%$ : denominated the "relative noise".

$\sigma:$ is the standard deviation measured in a $2 \mathrm{~cm}$ diameter ROI.

meanRoIval: is the average value of the Hounsfield Units measures taken on the ROI selected. 


\section{RESULTS AND DISCUSSION}

Table 3 shows the CTDI 100 values corrected by an air / PMMA conversion factor of 1.042 (related to the radiation spectrum mean energy, i.e. $72 \mathrm{keV}$, for beams obtained through a $120 \mathrm{kV}$ tube voltage $)^{9,10}$ to obtain the TC dose indexes on PMMA (CTDI $\left.I_{P M M A, 100}\right)$ for each phantom in each of the five holes (Fig 2) applying the protocol shown in Table 1. The measured minimum value was $5.93 \mathrm{mGy}$ and the highest of $21.94 \mathrm{mGy}$. The minimum dose is given in the central position for the adult phantom and in position 3 for the pediatric phantom. In this phantom also, the central dose is greater than those obtained in positions 6 and 9. In addition, all doses presented in table 3, for the pediatric phantom are higher than those of the adult phantom. The comparison between the CTDI ${ }_{W}$ values presented in Table 3 shows that the pediatric $C T D I_{W}$ is $89.5 \%$ greater than that obtained by applying the protocol shown in Table 1 for the adult patient phantom

Table 3: $C T D I_{P M M A, 100}$ and $C T D I_{W}$ values in mGy.

\begin{tabular}{ccccc}
\hline Position & \multicolumn{4}{c}{ Phantom } \\
\hline & Adult & \multicolumn{3}{c}{ Pediatric } \\
\hline CT DI $\boldsymbol{P M M A , 1 0 0}^{*}$ & SD $^{*}$ & $\boldsymbol{C T D I}_{\boldsymbol{P M M A}, \mathbf{1 0 0}}$ & SD \\
\hline $\mathbf{C}$ & 5.93 & 0.01 & 18.41 & 0.33 \\
\hline $\mathbf{3}$ & 12.35 & 0.08 & 17.95 & 0.24 \\
\hline $\mathbf{6}$ & 11.01 & 0.06 & 20.20 & 0.23 \\
\hline $\mathbf{9}$ & 12.52 & 0.01 & 18.20 & 0.29 \\
\hline $\mathbf{1 2}$ & 13.03 & 0.32 & 21.94 & 0.23 \\
\hline $\boldsymbol{C T D} \boldsymbol{I}_{\boldsymbol{W}}$ & 10.13 & 0.08 & 19.20 & 0.28
\end{tabular}

SD: standard deviation on each set of measurements.

In Table 4, the $C T D I_{W}$ values of are presented after having applied the protocols shown in Table 2. In addition, the $C T D I_{v o l}$ values for each case are presented. The optimized protocol for two years old patient returned a $C T D I_{v o l}$ of $7.9 \mathrm{mGy}$ representing a reduction of $62.2 \%$ in relation to the value obtained in the adult protocol examination. 
Table 4: Calculated $C T D I_{W}$ and $C T D I_{V O L}$ values in $\mathrm{mGy}$.

\begin{tabular}{ccc}
\hline Protocol & $\boldsymbol{C T D I}_{\boldsymbol{W}}(\boldsymbol{m G} \boldsymbol{y})$ & $\boldsymbol{C T D I}_{\boldsymbol{V O L}}(\boldsymbol{m G} \boldsymbol{y})$ \\
\hline Adult & 27.23 & 20.63 \\
\hline Pediatric optimized & 10.31 & 7.86 \\
\hline
\end{tabular}

Figure 3 shows the ROIs used for noise measurement through the standard deviation of the Hounsfield units (HU) in the central slice image obtained after applied the pediatric optimized protocol. The evaluations were made using the RadiAnt DICOM Viewer® software. In table 5, the mean ROI values and the associated standard deviations in $\mathrm{HU}$ are presented. Also, the $\% \mathrm{~N}$ value obtained for this protocol is shown.

Figure 3: Regions of Interest used for noise measurement.

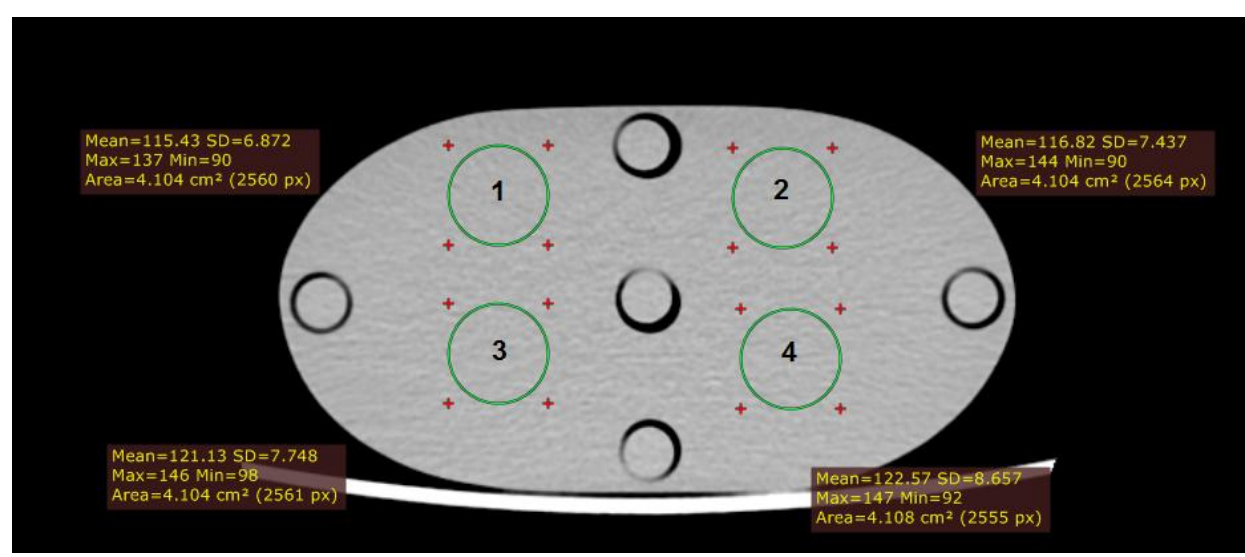

Table 5. Mean ROI values and associated standard deviations used for noise calculation.

\begin{tabular}{ccc}
\hline ROI & mean $($ HU) & $\boldsymbol{\sigma}$ \\
\hline 1 & 115.43 & 6.87 \\
\hline 2 & 121.13 & 7.75 \\
\hline 3 & 122.57 & 8.66 \\
\hline 4 & 116.82 & 7.44 \\
\hline Mean & 118.99 & 7.68 \\
\hline N & & 0.69 \\
\end{tabular}




\section{CONCLUSION}

The research presented shows the necessity to use exclusive protocols for pediatric patients. Otherwise, two years old pediatric patients may receive doses close to two times of an adult patient by examination. In this study, the use of the same adult protocol in children has involved an $89.5 \%$ higher dose.

The optimized protocol shows that changing current and maintain voltage constant, it is possible to decrease the doses while maintaining the quality of the image, compared to the adult protocol, it has achieved a decrease of $62.2 \%$ in the dose maintaining the noise percentage below $1 \%$.

The use of pediatric phantoms is necessary, since it is a tool that allows the testing of protocols that optimize the dose, allowing adapting to the anatomical reality of the patient.

In future works these results will be obtained using phantoms whose form depends on the age of the patient, varying other acquisition parameters, such as $\mathrm{kV}$, in order to better understand how the dose absorbed by the patient varies according to the shape of the patient and tomograph parameters.

\section{ACKNOWLEDGMENT}

This project had the support of the Research Foundation of Minas Gerais (FAPEMIG) and the authors thank the Technology Center of Molecular Image (CTIM) of the Federal University of Minas Gerais (UFMG).

\section{REFERENCES}

[1] AAPM - The American Association of Physicists in Medicine. Size-Specific Dose Estimates (SSDE) in Pediatric and Adult Body CT Examinations, AAPM report 204, AAPM, 2011. $30 \mathrm{p}$.

[2] VASSILEVA, J.; REHANI, M. M.; AL-DHUHLI, H.; AL-NAEMI, H. M.; AL-SUWAIDI, J. S.; APPELGATE, K.; ... \& BIEGANSKI, T. IAEA survey of pediatric CT practice in 40 countries in Asia, Europe, Latin America, and Africa: Part 1, frequency and appropriateness. Am J of Roentgenology, v. 198, no 5, p. 1021-1031, 2012. 
[3] ABURJAile, W. N.; MOURAO, A. P. Development of a chest phantom for testing in Computed Tomography scans. Radiation Physics and Chemistry, v. 140, p 275-277, 2017.

[4] TASK GROUP ON CONTROL OF RADIATION DOSE IN COMPUTED TOMOGRAPHY. Managing patient dose in computed tomography. A report of the International Commission on Radiological Protection. Annals of the ICRP, v. 30, no 4, p. 7, 2000.

[5] MCCOLlOUGH, C.; CODY, D.; EDYVEAN, S.; GEISE, R.; GOULD, B.; KEAT, N., ... \& MORIN, R. The measurement, reporting, and management of radiation dose in CT. Report of AAPM Task Group, v. 23, no 23, p. 1-28. 2008

[6] ANDISCO, D.; BLANCO, S.; BUZZI, A.; BALLESTER, S, Optimización Interdisciplinaria de Protocolos en Tomografía Computada a partir de la modificación del mA y del control del ruido en la imagen. Revista Argentina de Radiología, v. 74, no 4, p. 397-402. , 2010.

[7] BROSED, A.; RUIZ, P.; Fundamentos de Física Médica, SEFM, v.2, Madrid: ADI, 2012.

[8] CUNHA, L.; Estudos dosimétricos das varreduras de cabeça em tomografia computadorizada: avaliação da qualidade de imagem visando à otimização de protocolos, Universidad Federal de Minas Gerais, F363e, Bibliografía f: 91-94, CDU: 621.039(043), 2018.

[9] LADINO, M. Estudo de dosimetría e qualidade de imagem em varreduras de tomografía computadorizada de cabeça utilizando objeto simulador, Trabajo de Posgraduación, Universidad Federal de Minas Gerais, L155e, Anexo f:75, Bibliografía f: 72-74, CDU: 621.039(043), 2017.

[10] DUAN, X., WANG, J., YU, L., LENG, S., MCCOLLOUGH, C. H. CT scanner X-ray spectrum estimation from transmission measurements. Medical physics, v. 38(2), p. 993-997, 2011 